Boletín de la Sociedad Geológica Mexicana

VOLUMEN 68, NÚM. 2, 2016, P. 371

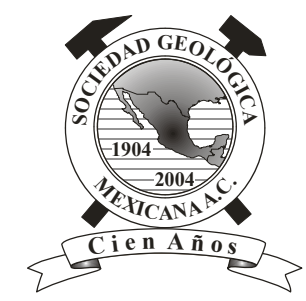

\title{
Addendum \\ Calisiopsis azteca n. sp., the first Aradidae from mid Miocene Mexican Amber (Hemiptera: Heteroptera)
}

\author{
Ernst Heiss ${ }^{1, *}$ \\ ${ }^{1}$ Tiroler Landesmuseum Ferdinandeum, Josef-Schraffl-Strasse 2a, A-6020 Innsbruck, Austria. \\ *aradus@aon.at
}

In the recent paper by Heiss (2016), one new species of Aradidae in Mexican amber was published without the Zoobank registration number. The taxa was registered before publication but missed the end phase of edition. Here we provide the number in order to make the new taxa valid according to the ICZN regulations:

\section{Calisiopsis azteca n.sp.}

urn:lsid:zoobank.org:pub:5B2FECF7-78C0-4EA5-8B62-D35CDE2DD429

\section{Reference}

Heiss, E., 2016, Calisiopsis azteca n. sp., the first Aradidae from mid Miocene Mexican Amber (Hemiptera: Heteroptera): Boletín de la Sociedad Geológica Mexicana, 68 (1), 7-10.

Manuscript received: May 12, 2016.

Manuscript accepted: May 13, 2016. 